\title{
Kommende Kurser
}

- 8. oktober 2014 Basal UL-vejledt Intervention, Odense, $\mathrm{OUH}$

27. oktober 2014

Klinisk ultralyd - (praksis)lægens nye værktøj, CEKU, Rigshospitalet

- 5-7. november 2014 DUDS، 18. kursus i Muskuloskeletal Ultralyd, Hvidovre Hospital

- 6. november 2014 USabcd, Basic FATE, GE Healthcare, Brøndby

6. november 2014

USabcd, Advanced FATE, GE Healthcare, Brøndby
- 7. november 2014 USabcd, Basic LUNG US \& FAST, GE Healthcare, Brøndby

7. november 2014

Basalkursus i UL af bevægeapparatet, CEKU, Rigshospitalet

- 10. november 2014 USabcd, Basic US Guided Nerve Blocks, GE Healthcare, Brøndby

- 10. november 2014

USabcd Advanced US Guided Nerve Blocks,GE Healthcare,Brøndby
- 13. September 2014 Ultralydkursus I Gynækologi og Obstetrik. Drejergaarden, Hvalsø

28. november 2014 Klinisk ultralyd - (praksis)lægens nye værktøj, Rigshospitalet

- 5. December 2014 Basalkursus I Doppler ultralyd. Rigshospitalet

Yderligere oplysninger om kurser, inklusive programmer, kan ses på www.duds.dk

\section{DUDS’ Efterårsmøde}

afholdes den 24.oktober 2014 kl. 13-17 i Auditorium 1, Tage Hansens Gade 2, 8000 Århus C 